\title{
Genome-wide association study of body weight in Australian Merino sheep reveals an orthologous region on OAR6 to human and bovine genomic regions affecting height and weight
}

Hawlader A. Al-Mamun ${ }^{1,2}$, Paul Kwan², Samuel A. Clark¹, Mohammad H. Ferdosi' ${ }^{1}$, Ross Tellam³ and Cedric Gondro ${ }^{1 *}$

\begin{abstract}
Background: Body weight (BW) is an important trait for meat production in sheep. Although over the past few years, numerous quantitative trait loci (QTL) have been detected for production traits in cattle, few QTL studies have been reported for sheep, with even fewer on meat production traits. Our objective was to perform a genome-wide association study (GWAS) with the medium-density Illumina Ovine SNP50 BeadChip to identify genomic regions and corresponding haplotypes associated with BW in Australian Merino sheep.

Methods: A total of 1781 Australian Merino sheep were genotyped using the medium-density Illumina Ovine SNP50 BeadChip. Among the 53862 single nucleotide polymorphisms (SNPs) on this array, 48640 were used to perform a GWAS using a linear mixed model approach. Genotypes were phased with hsphase; to estimate SNP haplotype effects, linkage disequilibrium blocks were identified in the detected QTL region.

Results: Thirty-nine SNPs were associated with BW at a Bonferroni-corrected genome-wide significance threshold of $1 \%$. One region on sheep (Ovis aries) chromosome 6 (OAR6) between 36.15 and $38.56 \mathrm{Mb}$, included 13 significant SNPs that were associated with BW; the most significant SNP was OAR6_41936490.1 $\left(P=2.37 \times 10^{-16}\right)$ at $37.69 \mathrm{Mb}$ with an allele substitution effect of $2.12 \mathrm{~kg}$, which corresponds to 0.248 phenotypic standard deviations for BW. The region that surrounds this association signal on OAR6 contains three genes: leucine aminopeptidase 3 (LAP3), which is involved in the processing of the oxytocin precursor; NCAPG non-SMC condensin I complex, subunit G (NCAPG), which is associated with foetal growth and carcass size in cattle; and ligand dependent nuclear receptor corepressor-like (LCORL), which is associated with height in humans and cattle.
\end{abstract}

Conclusions: The GWAS analysis detected 39 SNPs associated with BW in sheep and a major QTL region was identified on OAR6. In several other mammalian species, regions that are syntenic with this region have been found to be associated with body size traits, which may reflect that the underlying biological mechanisms share a common ancestry. These findings should facilitate the discovery of causative variants for BW and contribute to marker-assisted selection.

\footnotetext{
*Correspondence: cgondro2@une.edu.au

'School of Environmental and Rural Science, University of New England,

Armidale, NSW 2351, Australia

Full list of author information is available at the end of the article
} 


\section{Background}

In sheep, body weight (BW) is an important economic trait for meat production. Currently, genome-wide association studies (GWAS) are applied to identify candidate genes for many quantitative traits, not only in sheep, but also in many other species [1-6]. Several GWAS for growth and meat production traits in cattle have been published in recent years [7-9]. GWAS for bovine carcass weight and other production traits have revealed major quantitative trait loci (QTL) on chromosomes (BTA for Bos taurus) BTA6, 8, 11, 14, 24 and 25 [10-12]. For carcass weight, QTL have been reported in a $1.1 \mathrm{Mb}$ region on BTA14 and a $591 \mathrm{~kb}$ region on BTA6 by Mizoshita et al. [10] and Setoguchi et al. [12], respectively. Nishimura et al. [11] also identified three major QTL for carcass weight in Japanese black cattle on BTA6, 8 and 14, which together explained approximately one-third of the genetic variance of carcass weight. Karim et al. [13] mapped a QTL to a $780 \mathrm{~kb}$ region on BTA14 that had a major effect on bovine stature. The QTL region on BTA14 contains six genes that are associated with stature in both cattle and humans [14-17]: pleiomorphic adenoma gene 1 (PLAG1), coiled-coil-helix-coiled-coil-helix domain containing 7 (CHCHD7), proenkephalin (PENK), V-Mos Moloney murine sarcoma viral oncogene homolog (MOS), V-Yes1 Yamaguchi sarcoma viral related oncogene homolog $(L Y N)$ and trimethylguanosine synthase 1 (TGS1). The same QTL region on BTA14 has also been shown to affect birth weight and size in zebu cattle (Bos primigenius indicus) [18]. In addition, Lee et al. [19] detected a major QTL on BTA14 for carcass weight in Korean cattle (Hanwoo), which explained at least $10 \%$ of the genetic variation of carcass weight in this breed. In brown Swiss cattle, 74 genome-wide significant single nucleotide polymorphisms (SNPs) were shown to be associated with one or more production traits, including fertility, conformation, udder health and workability on BTA6, 11, 24 and 25 [20].

Although many GWAS have identified important candidate genes in different species, there are comparatively few QTL studies for sheep. To date, 801 ovine QTL are curated in the Sheep QTLdb [21], among which only a very small number concern meat production. Most of the QTL studies that have been performed on sheep were based on sparse microsatellite markers that exhibited large QTL confidence intervals, which makes it very difficult to identify candidate genes for the targeted quantitative trait. In sheep, few GWAS have focused on growth and meat production traits [22-24] and among these, only one study reported a GWAS and fine mapping of QTL for BW, on ovine (Ovies aries) chromosome 21 (OAR21) [24].

In this study, our aims were (1) to perform a GWAS to detect significant SNPs that are associated with BW in sheep by using data from 1781 Australian Merino sheep genotyped with the Illumina Ovine SNP50 BeadChip and (2) to explore the genomic regions around these SNPs for candidate genes.

\section{Methods}

\section{Ethical statement}

Samples for genotyping were collected under approval number 344 AEC12-049 of the University of New England Animal Ethics Committee.

\section{Phenotypic data}

The data used in this study consisted of phenotypic records from 1781 half-sib family groups of Merino sheep from the Australian Sheep CRC Information Nucleus flock, which included 1088 males and 693 females sired by 111 sires. The maximum and minimum numbers of sheep per sire group were 49 and 1, respectively. Postweaning weight, which is an early life body weight measurement, was measured at an average age of 287.5 days, with a minimum of 148 days and a maximum of 431 days. Body weights ranged from 17.5 to $67.2 \mathrm{~kg}$, with an average of $39.7 \mathrm{~kg}$, and were normally distributed.

\section{Genotyping and quality control}

All animals were genotyped using the Illumina Ovine SNP50 BeadChip (Illumina Inc., San Diego, CA, USA), which includes 53862 SNPs. Quality control was performed with the $\mathrm{R}$ program $\operatorname{sn} p Q C$ and SNPs were filtered as follows: SNPs were removed if they had a call rate less than $95 \%$, a GenCall score less than 0.6, a minor allele frequency lower than 0.01 and if their heterozygosity rate was outside the interval of the mean $\pm 3 \times$ standard deviations ( mean heterozygosity rate $=0.37$ and s.d. $=0.13$ ). SNPs that departed from Hardy-Weinberg equilibrium (for a $P$-value cut-off of $1 \times 10^{-15}$ ) or had no assigned genomic location or were located on the sex chromosomes were also excluded from the analyses. Missing genotypes were imputed using fast PHASE [25].

\section{Statistical analyses}

A GWAS was performed with a linear mixed effects model using ASREML [26]. The following fixed effects were fitted in the model: sex, birth type, rearing type, age of dam, contemporary group (birth year * birth month * site " management group) and age at trait recording. To account for family effects, sire was also fitted as a random effect (sire model with pedigree). The additive allelic substitution effect was individually calculated for each SNP by fitting the following mixed model:

$$
\mathbf{y}=\mathbf{X b}+\mathbf{Z g}+\varepsilon
$$

where, $\mathbf{y}$ is a vector of individual body weights, $\mathbf{X}$ is a design matrix for fixed effects (as described above) and SNP genotypes fitted as covariate, and $\mathbf{b}$ is a vector of 
fixed and SNP effects. $\mathbf{Z}$ is a matrix that allocates records to sire, $\mathbf{g}$ is a vector of sire effects, and $\varepsilon$ is the residual. After fitting the data in model (1), analysis of the residuals indicated that the model was reliable and did not violate the statistical assumption of normality. $P$-values were adjusted for multiple-testing to a 0.01 Bonferroni-corrected significance threshold $\left(P<2.05 \times 10^{-7}\right)$. To evaluate if estimates were overinflated, we calculated the genomic inflation factor $\lambda$ using the GenABEL R package [27].

The percentage of genetic variance explained by each significant SNP was calculated according to the following formula:

$$
\% V_{g i}=100 \times 2 p_{i} q_{i} a_{i}^{2} / \sigma_{g}^{2},
$$

where $p_{i}$ and $q_{i}$ are the allele frequencies for the $i^{\text {th }} \mathrm{SNP}, a_{i}$ is the estimated additive effect of the $i^{\text {th }} \mathrm{SNP}$ on BW, and $\sigma_{g}^{2}$ is the estimated genetic variance. ASReml [26] was used to estimate heritability $\left(h^{2}\right)$ and genetic variance for BW using the same data and model as Eq. 1, however without including SNP effects.

Estimation of the genetic variance attributable to each individual chromosome was done using the GCTA [28] software. A genomic relationship matrix was built for each of the 26 autosomes using only the SNPs mapped to each of the chromosomes. All chromosomes were then fitted simultaneously in GCTA using the 26 GRM.

Identification of haplotype blocks and regression analyses The hsphase algorithm [29] was used to reconstruct haplotypes on OAR6. Since this algorithm relies on a minimum number of individuals in a half-sib family, we opted for a conservative approach and excluded half-sib families that had less than 10 individuals. Thus, paternal and maternal haplotypes for OAR6 were phased for 1569 individuals. Missing alleles in the haplotypes were imputed with BEAGLE 3.3.2 [30]. Finally, the regions that contained significant SNPs were selected for haplotype analyses (45 SNPs in the region between 36.15 and $38.56 \mathrm{Mb}$ ).

Linkage disequilibrium (LD) between SNPs within the region between 36.15 and $38.56 \mathrm{Mb}$ on OAR6 was calculated as $\left|D^{\prime}\right|$, using Haploview (V4.2 [31]). LD blocks were generated for SNPs that were separated by less than $500 \mathrm{~kb}$, as proposed by Gabriel et al. [32]. Haplotype association analyses were performed using the following multiple regression mixed model equation:

$$
y_{j}=\mu+\sum_{i=1}^{t} \beta_{i j} H_{i}+S_{j}+e_{i j}
$$

where $y_{j}$ is the residual phenotypic value for the $j^{\text {th }}$ individual after adjusting for the fixed effects (Eq. 1); $\mu$ is the overall mean; $\beta_{i j}$ is the haplotype score $(0,1$, or 2$)$ of the $i^{t h}$ haplotype for the $j^{\text {th }}$ individual, with $t$ the number of haplotypes segregating in the population for that region;
$H_{i}$ is the effect of the $i^{t h}$ haplotype; $S_{j}$ is the random sire effect, and $e_{i j}$ is the random residual effect.

\section{Results}

Descriptive statistics and quality control

From the initial set of 53862 SNPs, 1449 (2.69 \%) nonautosomal SNPs, 1662 SNPs with a minor allele frequency lower than $0.01,1838$ SNPs with a call rate $\left(\mathrm{CR}_{\mathrm{SNP}}\right)$ less than 0.95 , and 273 SNPs that departed from the Hardy-Weinberg equilibrium were removed. No individual was excluded because of a call rate $\left(\mathrm{CR}_{\mathrm{IND}}\right)$ lower than 0.7 , but 38 individuals were excluded because of missing phenotypes. After quality control, 1743 individuals and 48640 SNPs were retained for analysis.

The number and the average distances between adjacent SNPs on each chromosome, before and after filtering, are in Table S1 [See Additional file 1: Table S1]. Before quality control, the number of SNPs on each chromosome ranged from 741 on OAR24 to 5930 on OAR1, while average adjacent distances ranged from $44.1 \mathrm{~kb}$ on OAR8 to $56.8 \mathrm{~kb}$ on OAR24. After quality control, the number of SNPs on each chromosome ranged from 679 on OAR24 to 5494 on OAR1 and average adjacent distances ranged from $47.2 \mathrm{~kb}$ on OAR8 to $66.2 \mathrm{~kb}$ on OAR21.

\section{Association analyses}

The GWAS identified one major region with a strong association with BW between 36.15 and $38.56 \mathrm{Mb}$ on OAR6 (Fig. 1 top panel). To reduce the detection of spurious associations, GWAS results were smoothed with a running median of the $P$-values that spanned five adjacent SNPs (Fig. 1 lower panel). For SNPs with $P$-values less than 0.01 , the quantile-quantile $(\mathrm{Q}-\mathrm{Q})$ plot revealed a large deviation from the distribution under the null hypothesis, which indicated a strong association between this region and BW (Fig. 2). Significant Bonferroni-corrected genome-wide associations $\left(P<2.05 \times 10^{-7}\right)$ were detected for 39 SNPs [See Additional file 2: Table S2], of which 13 were located on OAR6 (Table 1). Among the five most significant SNPs, four were located on OAR6 and, out of these, the most significant was OAR6_41936490.1 $\left(P=2.36 \times 10^{-16}\right)$, which is located at $37.69 \mathrm{Mb}$. The other three SNPs on this chromosome were s17946.1 $\left(P=7.97 \times 10^{-14}\right)$ at $37.1 \mathrm{Mb}$, OAR6_41877997.1 $\left(P=2.49 \times 10^{-12}\right)$ at $37.64 \mathrm{Mb}$, and OAR6_41003295.1 $\left(P=2.4 \times 10^{-11}\right)$ at $36.81 \mathrm{Mb}$. Apart from this region on OAR6, the most significant SNP was on OAR3, i.e. OAR3_128968872.1 $\left(P=2.16 \times 11^{-16}\right)$ at $120.9 \mathrm{Mb}$. Four SNPs were detected on OAR14, at 23.5, 32.4, 52.2 and $57.9 \mathrm{Mb}$. The remaining significant SNPs were spread over various chromosomes [See Additional file 2: Table S2]. After smoothing, only the region between 36.15 and $38.56 \mathrm{Mb}$ on OAR6 exceeded the significance threshold. In this region, there were 45 SNPs on the array, 


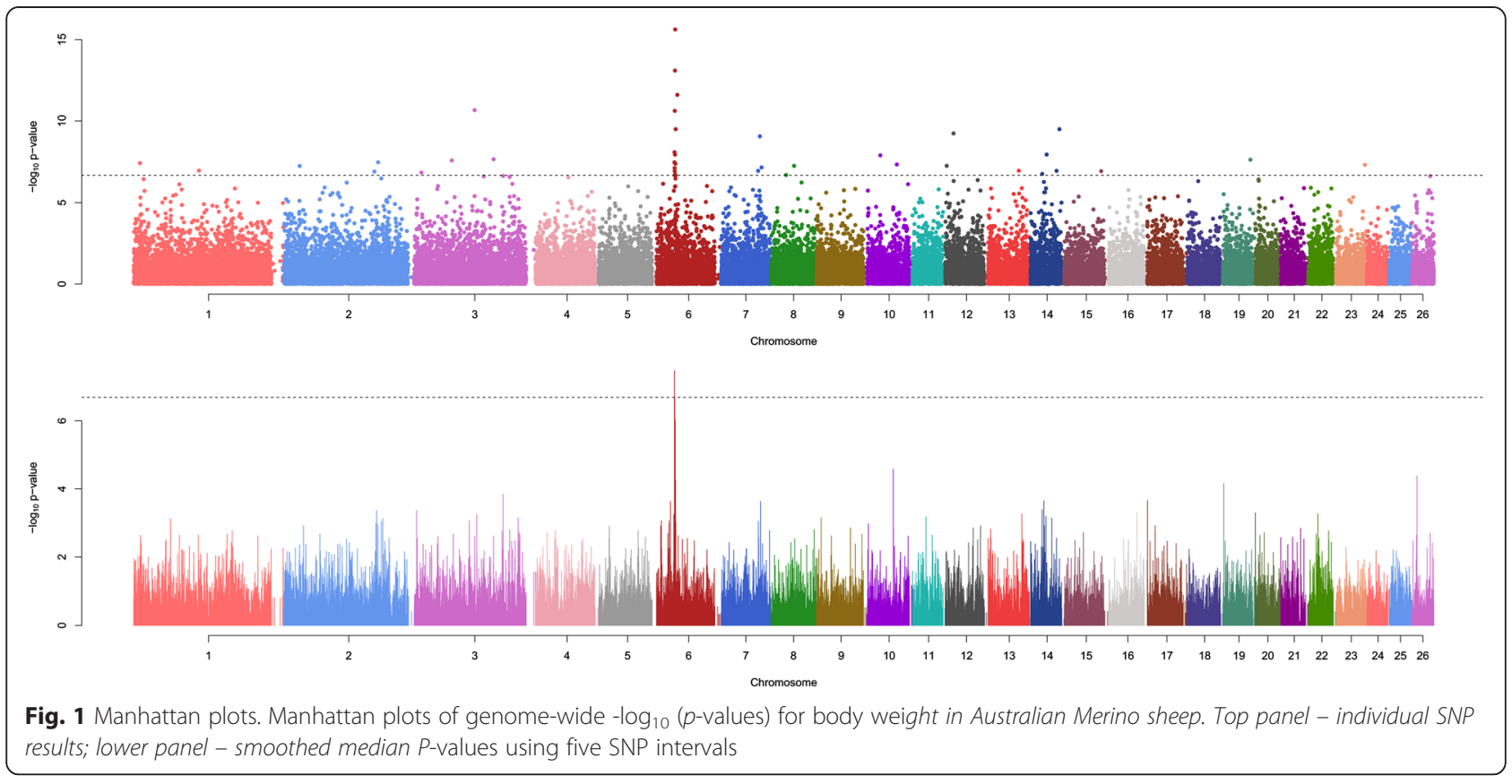

of which 30 were significantly associated with $\mathrm{BW}$ prior to Bonferroni correction (unadjusted $p$-value $<0.001$ ).

The patterns of LD in the region between 36.15 and $38.56 \mathrm{Mb}$ on OAR6 were investigated using |D'| (Fig. 3). One clear LD block of $104 \mathrm{~kb}$ was detected, with LD blocks defined following the criteria described in [32]). This block contained one of the genome-wide significant SNPs $\left(7^{\text {th }}\right.$ ranked), while the second most significant SNP was on its border (Fig. 3).

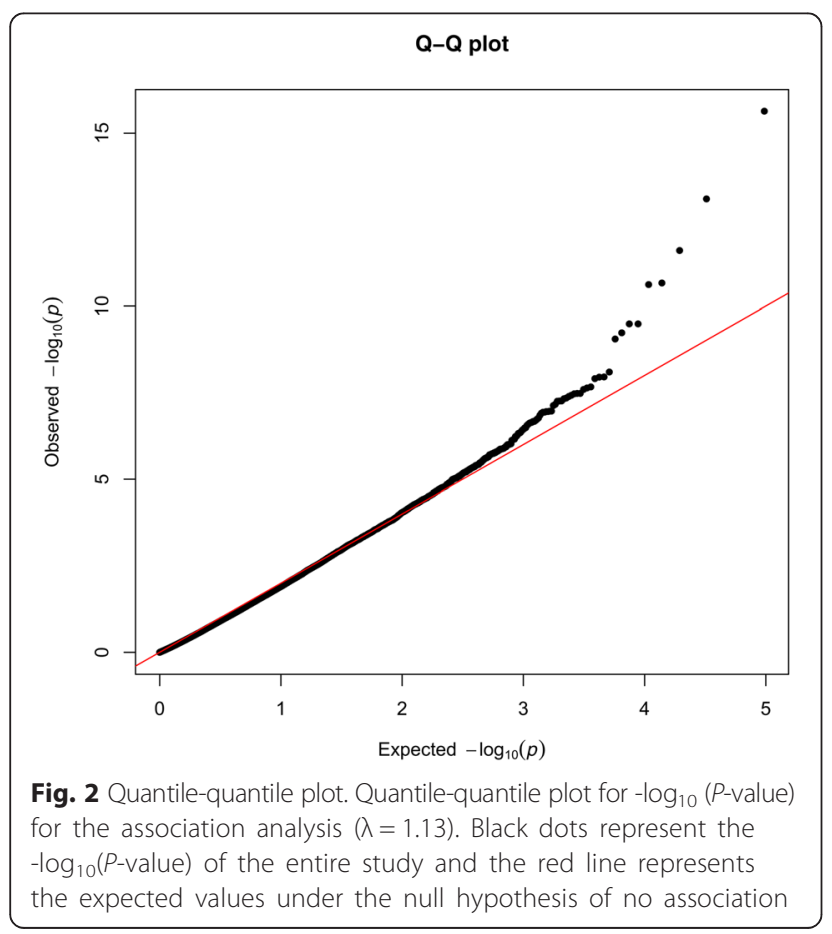

Based on the Ovis aries reference genome assembly (Oar_v3.1), the region between 36.15 and $38.56 \mathrm{Mb}$ on OAR6 contains 14 genes. These include NCAPG non$S M C$ condensin I complex, subunit G (NCAPG), which is associated with foetal growth and carcass size in cattle [33], and ligand dependent nuclear receptor corepressor-like (LCORL), which is associated with height in humans and cattle $[14,15]$ (Table 2 and Fig. 4). The contig tracks in Fig. 5 show that a high level of sequence conservation was found between the $1.0 \mathrm{Mb}$ sequence of the OAR6 region around NCAPG and LCORL and the syntenic regions on BTA6, HSA4 (HSA for Homo sapiens chromosome) and SSC8 (SSC for Sus scrofa chromosome). When considering a larger 2.41 Mb region (Table 2), more genes were identified, as well as 12 previously reported QTL using different sheep breeds [21] (Table 3). These included QTL for average daily gain, body weight, milk yield, milk lactose yield, and milk fat percentage.

In our analysis, we calculated the proportion of additive genetic variance explained by each SNP for a Bonferroni adjusted $P$-value cut off threshold of 0.01 , detected by single-marker regression analysis. Although this variance could be overestimated because polygenic effects may not be fully accounted for, the most significant SNP explained a relatively large percentage $(7.22 \%)$ of the total additive genetic variance. The estimated heritability $\left(h^{2}\right)$ for BW was equal to 0.63 .

Allele substitution effects for the 13 significant SNPs on OAR6 ranged from 1.54 to $2.34 \mathrm{~kg}$. The most significant SNP (OAR6_41936490.1; $P=2.36 \times 10^{-16}$ ) had an allele substitution effect of $2.12 \mathrm{~kg}$, while the second most significant SNP $\left(s 17946.1 ; P=7.97 \times 10^{-14}\right)$ had an effect of 
Table 1 SNPS on OAR6 showing significant association with body weight in 1743 Merino sheep

\begin{tabular}{llllllllll}
\hline SNP & Position & Adjusted P-value & $\mathrm{n} 0$ & $\mathrm{n} 1$ & $\mathrm{n} 2$ & $\mathrm{p}$ & $\mathrm{q}$ & $\mathrm{v}_{\mathrm{g}}$ & $\beta(\mathrm{kg})$ \\
\hline OAR6_41936490.1 & 37694563 & $1.15 \times 10^{-11}$ & 119 & 706 & 918 & 0.271 & 0.729 & 6.17 & 2.116 \\
S17946.1 & 37164383 & $3.88 \times 10^{-09}$ & 83 & 630 & 1030 & 0.228 & 0.772 & 5.88 & -2.132 \\
OAR6_41877997.1 & 37640732 & $1.21 \times 10^{-07}$ & 110 & 650 & 983 & 0.250 & 0.750 & 6.05 & -1.876 \\
OAR6_41003295.1 & 36819342 & $1.17 \times 10^{-06}$ & 150 & 722 & 871 & 0.293 & 0.707 & 6.50 & -1.741 \\
OAR6_42945420.1 & 38567455 & $1.56 \times 10^{-05}$ & 22 & 321 & 1400 & 0.105 & 0.895 & 6.54 & 2.28 \\
OAR6_40449774.1 & 36234302 & $3.87 \times 10^{-04}$ & 20 & 378 & 1345 & 0.120 & 0.880 & 6.62 & -2.079 \\
OAR6_41558126.1 & 37334387 & $5.45 \times 10^{-04}$ & 79 & 574 & 1090 & 0.210 & 0.790 & 6.30 & 1.686 \\
OAR6_40409402.1 & 36192023 & $1.61 \times 10^{-03}$ & 9 & 254 & 1480 & 0.078 & 0.922 & 6.65 & 2.337 \\
OAR6_40370293.1 & 36155169 & $1.65 \times 10^{-03}$ & 110 & 641 & 992 & 0.247 & 0.753 & 6.25 & -1.589 \\
OAR6_42247197.1 & 37987281 & $1.97 \times 10^{-03}$ & 60 & 512 & 1171 & 0.181 & 0.819 & 6.52 & -1.645 \\
OAR6_40724811_X.1 & 36522166 & $3.61 \times 10^{-03}$ & 18 & 385 & 1340 & 0.121 & 0.879 & 6.26 & -1.914 \\
OAR6_40855809.1 & 36655091 & $5.65 \times 10^{-03}$ & 53 & 448 & 1242 & 0.159 & 0.841 & 6.34 & 1.612 \\
OAR6_41768532.1 & 37533664 & $9.01 \times 10^{-03}$ & 64 & 521 & 1158 & 0.186 & 0.814 & 6.46 & 1.542 \\
\hline
\end{tabular}

Thirteen SNPs on OAR6 reach the genome-wide significance level (adjusted $P$-value $<0.01$ ). These SNPs span the region between 36.15 and $38.56 \mathrm{Mb}$. A total of 45 SNPs on the Illumina Ovine SNP50 BeadChip are mapped to this region and 30 were identified as significant for an unadjusted $p$-value threshold of 0.001 . n0, $\mathrm{n} 1$, and $\mathrm{n} 2$ are the number of individuals with 2,1 and 0 copies of the minor allele; $\mathrm{p}$ is the minor allele frequency and $\mathrm{q}=1-\mathrm{p}$; $\mathrm{Vg}$ indicates the proportion of the genetic variance that is attributable to each SNP estimated by ASReml (note that SNPs are not unlinked and the sum of effects will be overestimated). $\beta$ is the allele substitution effect. SNP positions are based on the Oar_v3.1 assembly of the ovine genome sequence

$2.13 \mathrm{~kg}$, corresponding respectively to 24.82 and $29.5 \%$ of the phenotypic standard deviation for BW (Table 1 and Fig. 6). However, it should be noted that these two SNPs are in LD and most likely track the same QTL.

We also calculated the percentage of genetic variance explained by each chromosome and found that OAR6 explained $7.71 \%$ of the additive genetic variance [See Additional file 3: Table S3]. Although OAR12 explained the largest proportion of the variance, i.e. $8.91 \%$, only two significant SNPs were detected on this chromosome by single-SNP regression analysis (Fig. 1).

\section{Haplotype analyses}

A haplotype analysis of the region between 36.15 and $38.56 \mathrm{Mb}$ on OAR6 was carried out and SNPs that were in high LD within this region were grouped together in haplotype blocks. Using the criteria specified by Gabriel et al. [32], a haplotype block of 104 kb was identified. This haplotype block contains four SNPs (OAR6_41476497.1, OAR6_41494878.1, OAR6_415581 26.1, OAR6_41583796.1), which were all significantly associated with BW prior to Bonferroni correction (unadjusted $p$-value $\leq 0.0001$ ). $\left|\mathrm{D}^{\prime}\right|$ values between SNPs in this block ranged from 0.97 to 1.00 (Fig. 3). Seven distinct haplotypes were detected in this block. Using Eq. (3), these haplotypes were shown to have a highly significant $(p$-value $<0.0008)$ effect on sheep BW. Haplotypes AGGT and GATC showed significant but opposite effects, while haplotype GATT had a marginal effect on BW (Table 4). By visual inspection (Fig. 3), we found that two other neighbouring SNPs, outside the haplotype block, were also in high LD with the SNPs in this haplotype block. Thus, we extended the haplotype blocks to include these two additional SNPs in the haplotype analysis. We found that these haplotype blocks also had significant associations with $\mathrm{BW}$, with a $p$-value less than 0.001 for a block of $223 \mathrm{~kb}$ (SNPs OAR6_41476497.1, OAR6_41494878.1, OAR6_41558126.1, OAR6_415837 96.1 and OAR6_41709987.1), and less than 0.006 for a block of $278 \mathrm{~kb}$ (SNPs OAR6_41476497.1, OAR 6_41494878.1, OAR6_41558126.1, OAR6_41583796.1, OAR6_41709987.1 and OAR6_41768532.1).

\section{Discussion}

In this study, we performed a GWAS on Australian Merino sheep by genotyping data using a medium-density chip that included around 50000 SNPs. The analysis identified 13 SNPs that spanned a $2.41 \mathrm{Mb}$ region on OAR6 that were significantly associated $(\mathrm{P}<0.001)$ with $\mathrm{BW}$. Biologically relevant genes in this region are ATP-binding cassette sub-family G member 2 (ABCG2), polycystin-2 (PKD2), leucine aminopeptidase 3 (LAP3), NCAPG non$S M C$ condensin I complex, subunit G (NCAPG), and ligand dependent nuclear receptor corepressor-like (LCORL). Chromosomal locations and known functions of these genes are in Table 2. A causative mutation in the ABCG2 gene was previously reported to affect milk yield and composition in dairy cattle [34]. The LAP3 gene encodes leucine aminopeptidase, which is associated with milk production traits in cattle [35]. In humans, the LCORL gene encodes a ligand dependent nuclear corepressorlike transcription factor and polymorphisms in this gene are associated with skeletal frame size and adult 


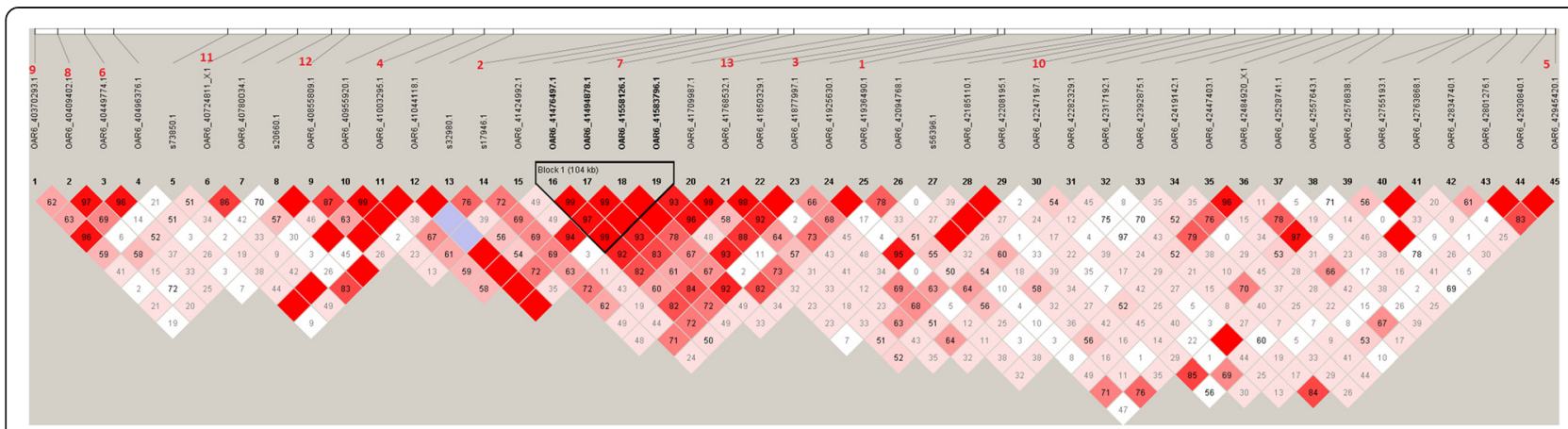

Fig. 3 Linkage disequilibrium (LD) map. Extent of $L D$ across the $2.41 \mathrm{Mb}$ region between 36.15 and $38.56 \mathrm{Mb}$ on OAR6. At the top of the figure, the 13 significant SNPs identified in this region are highlighted in red by order of significance. The haplotype block of $104 \mathrm{~kb}$ containing four SNPs is shown in bold black

height (http://www.ncbi.nlm.nih.gov/). In cattle, a nonsynonymous but chemically conserved variant in the NCAPG gene has been identified as a potential causative variant for body frame size [36]: height, length and width at puberty. However, this variant was excluded as the causal mutation for the QTL that affects fetal growth and carcass traits, and is located in the same region using data on a Charolais x Holstein cross [37]. Similarly, SNPs located in the equine NCAPG and LCORL genes have been reported to be associated with several body size traits [5].
We used LD to identify haplotype blocks associated with BW. In the region between 36.15 and $38.56 \mathrm{Mb}$ on OAR6, a haplotype block of four SNPs was identified that had a significant effect on BW in sheep. This haplotype block ranged from 37254883 to 37359421 bp and contained two functional candidate genes: NCAPG between 37362 103 and 37333949 bp and LCORL between 37362163 and $37488824 \mathrm{bp}$. Results are in agreement with several previous studies on different species, including sheep, cattle, horse and chicken. In a study on Scottish Blackface lambs, Riggio et al. [22] reported a region between 33.2

Table 2 List of known genes in the 36.15-38.56 Mb region on OAR6

\begin{tabular}{|c|c|c|c|c|c|c|c|}
\hline $\begin{array}{l}\text { Gene } \\
\text { symbol }\end{array}$ & NCBI Gene ID & OAR6 coordinates (bp) & $\begin{array}{l}\text { Distance from } \\
\text { most significant } \\
\text { SNP (kb) }\end{array}$ & $\begin{array}{l}\text { HSA4 } \\
\text { homology }\end{array}$ & $\begin{array}{l}\text { BTA6 } \\
\text { homology }\end{array}$ & $\begin{array}{l}\text { SSC8 } \\
\text { homology }\end{array}$ & Gene description \\
\hline HERC5 & 101119562 & $36197360 . .36244346$ & 1450 & 51191 & 514373 & 100518083 & $\begin{array}{l}\text { HECT and RLD domain containing E3 } \\
\text { ubiquitin protein ligase } 5\end{array}$ \\
\hline HERC6 & 101103321 & $36252541 . .36306667$ & 1387 & 55008 & 527520 & 100626657 & $\begin{array}{l}\text { HECT and RLD domain containing E3 } \\
\text { ubiquitin protein ligase family member } 6\end{array}$ \\
\hline PPM1K & 101119821 & $36397745 . .36421249$ & 1273 & 152926 & 540329 & 100723717 & $\begin{array}{l}\text { protein phosphatase, } \mathrm{Mg}^{2+} / \mathrm{Mn}^{2+} \\
\text { dependent, } 1 \mathrm{~K}\end{array}$ \\
\hline$A B C G 2$ & 780508 & 36445816.36556892 & 1137 & 9429 & 536203 & 397073 & $\begin{array}{l}\text { ATP-binding cassette, sub-family G (WHITE), } \\
\text { member } 2\end{array}$ \\
\hline PKD2 & 101103569 & $36564403 . .36630798$ & 1063 & 5311 & 530393 & 641309 & $\begin{array}{l}\text { polycystic kidney disease } 2 \\
\text { (autosomal dominant) }\end{array}$ \\
\hline SPP1 & 443058 & 36645289.36658205 & 1036 & 6696 & 281499 & 397087 & secreted phosphoprotein 1 \\
\hline MEPE & 101120244 & 36804572.36819432 & 875 & 56955 & 613958 & 100521206 & matrix extracellular phosphoglycoprotein \\
\hline IBSP & 101120495 & $36837345 . .36850895$ & 843 & 3381 & 281233 & 397137 & integrin-binding sialoprotein \\
\hline LAP3 & 101120750 & 37092323.37116174 & 578 & 51056 & 781648 & 100739583 & leucine aminopeptidase 3 \\
\hline MED28 & 101121011 & 37126382.37132492 & 562 & 80306 & 513972 & 425350 & mediator complex subunit 28 \\
\hline FAM184B & 101121264 & 37138515.37257047 & 437 & 27146 & 523874 & 100627969 & $\begin{array}{l}\text { family with sequence similarity } 184, \\
\text { member B }\end{array}$ \\
\hline DCAF16 & 101121517 & 37278542.37279451 & 415 & 54876 & 777600 & 100513483 & DDB1 and CUL4 associated factor 16 \\
\hline NCAPG & 101121775 & $37289107 . .37333949$ & 360 & 64151 & 531234 & 100513670 & non-SMC condensin I complex, subunit G \\
\hline LCORL & 101104320 & $37362103 . .37488824$ & 205 & 254251 & 540095 & 100337668 & $\begin{array}{l}\text { ligand dependent nuclear receptor } \\
\text { corepressor-like }\end{array}$ \\
\hline
\end{tabular}




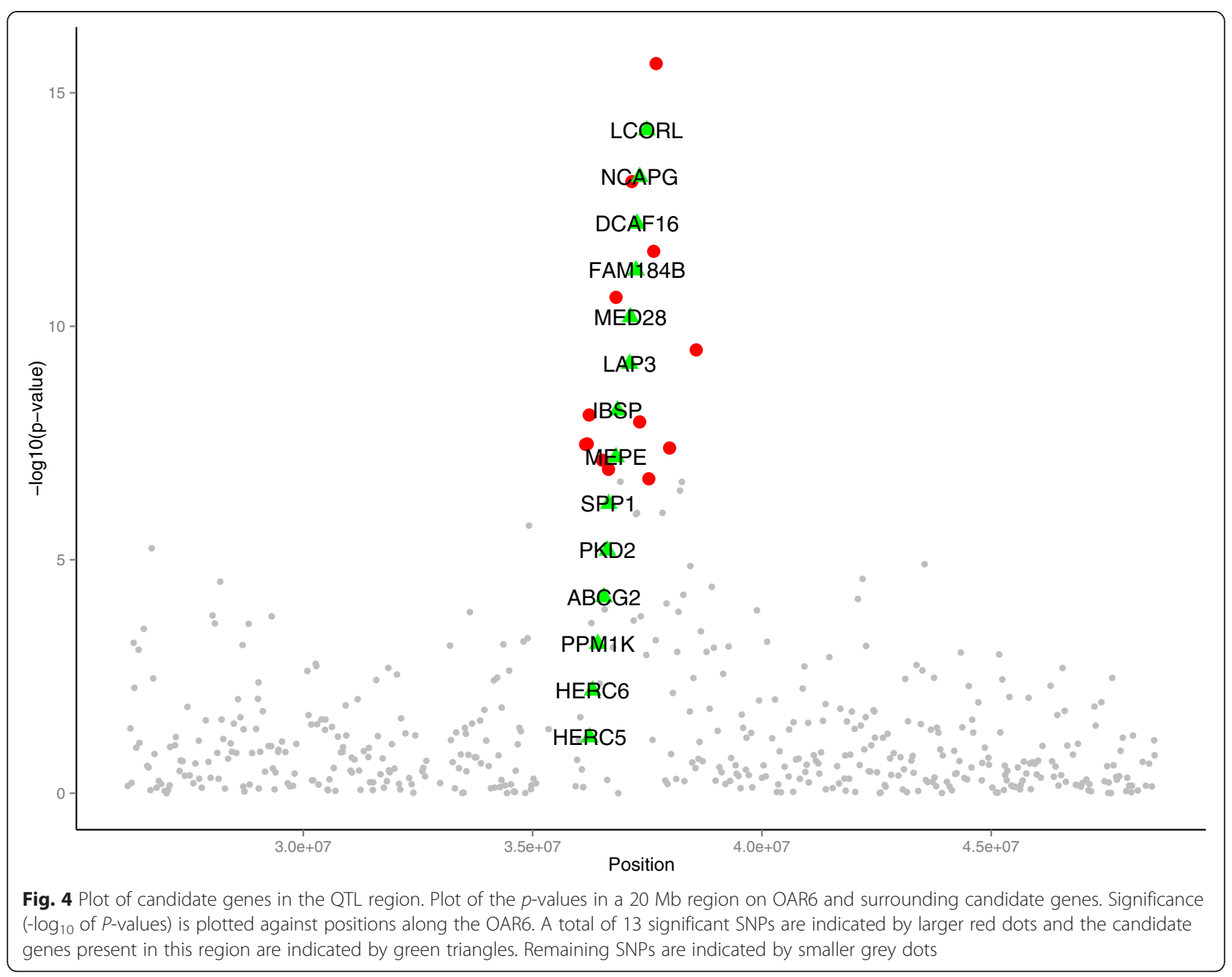

and $37.7 \mathrm{Mb}$ on OAR6 that contained several SNPs associated with BW at different ages (from 6 to 24 weeks old). This result agrees with the $36.15-38.56 \mathrm{Mb}$ region on OAR6 that we found to be significantly associated with BW. In Australian sheep, Daetwyler et al. [38] reported that SNP OAR6_41936490.1 (the most significant SNP in our study) was associated with lean meat yield (LMY) and that two other SNPs close to the region between 36.15 and $38.56 \mathrm{Mb}$ on OAR 6 were associated with carcass fat depth (FAT), intra-muscular fat (IMF) and dressing percentage (DRESS, calculated as the ratio of hot carcass weight to pre-slaughter weight) traits. In cattle, Setoguchi et al. [12] detected a QTL for carcass weight in a $591 \mathrm{~kb}$ interval on BTA6 and identified a causative gene variant in the NCAPG gene (NCAPG c.1326T > G, which changes the amino acid Ile442 to Met442 in the encoded protein). The NCAPG c.1326T > G variant is present in various bovine breeds and has been associated with birth weight [39], withers height and BW at adolescence [36, 40]. In Japanese Black cattle, Nishimura et al. [11] also identified a major QTL for carcass weight on BTA6. In horse, the NCAPG-
LCORL locus is located on ECA3 (ECA for Equus caballus chromosome) and a QTL located just upstream of the $L C O R L$ gene was found to be associated with height at the withers [5]. In our analysis, we also explored a larger region that surrounded the detected QTL and identified several relevant genes downstream of the QTL region i.e. $K v$ channel-interacting protein 4 (KCNIP4), G protein-coupled receptor 125 (GPR125) and glucosidase, beta, acid 3 (GBA3). Recently, a region containing the chicken orthologous KCNIP4 and GPR125 genes was identified in the region between 71.6 and $80.2 \mathrm{Mb}$ on GGA4 (GGA for Gallus gallus chromosome) and was shown to be associated with BW and average daily weight gain from 6 to 12 weeks [2].

Alignment of the NCPAG-LCORL region on OAR6 and syntenic regions in other mammalian species showed a high level of sequence similarity (Fig. 5), which supports both structural and functional conservation. This suggests that the orthologous genes that are located in a conserved region were maintained by evolution even after speciation from a common ancestor of the 


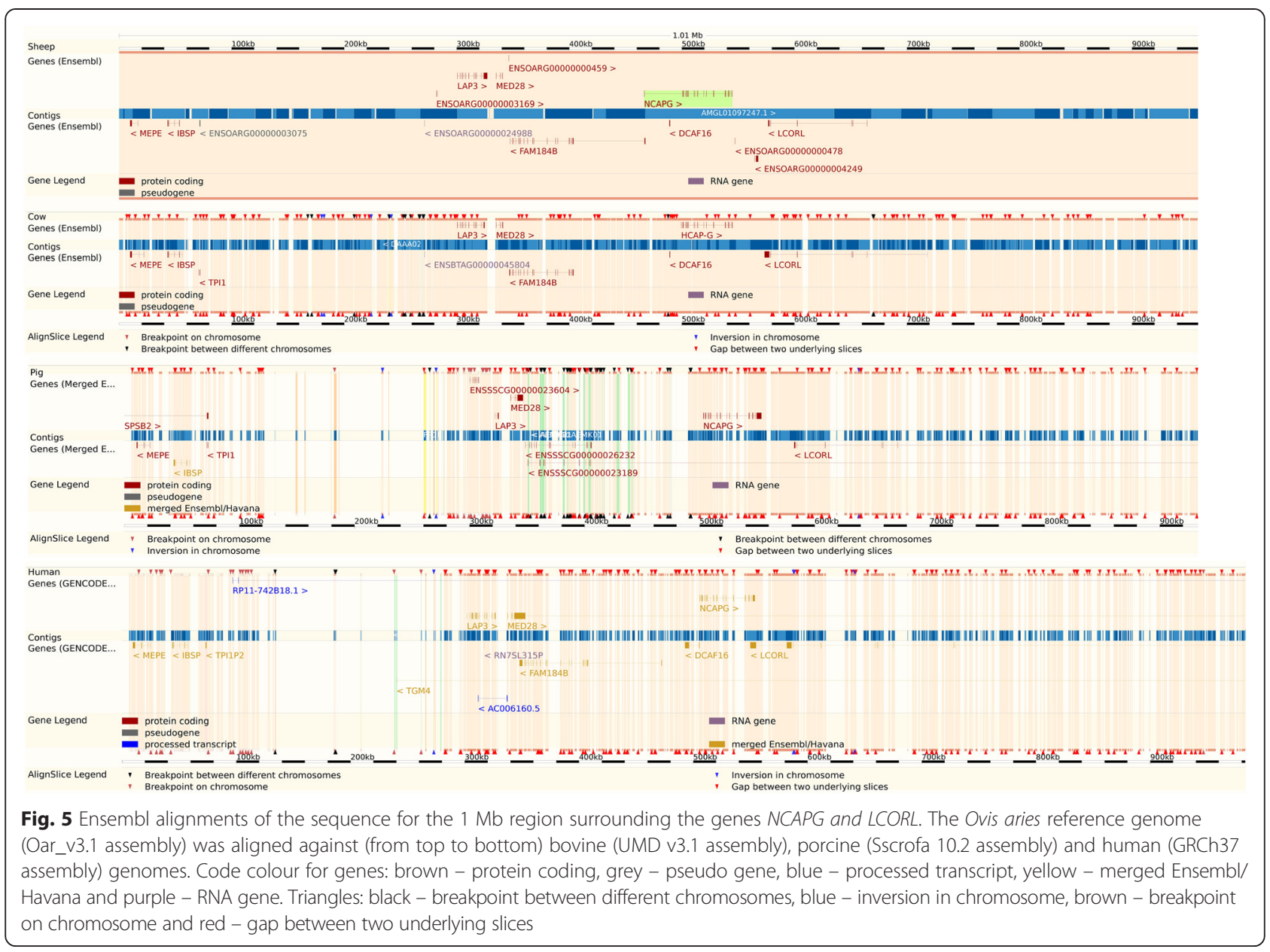

mammalian clade. Since there are multiple body size traits linked to the broader $2.41 \mathrm{Mb}$ region in many mammalian species, it is likely that there is a common underlying biological mechanism, i.e. loss or gain of function of a single gene through species-specific mutations. Interestingly, this region is also associated with calving ease, which may represent an indirect trait for body size [41, 42] and fetal growth [39] in cattle and also with human birth weight [43]. These results suggest the action of a gene that is involved in the developmental processes before birth, and which continues to have an effect on the adult.

Table 3 QTLdb hits within regions surrounding the 36.15-38.56 Mb interval on OAR6

\begin{tabular}{llll}
\hline Trait & OAR6 Coordinate & QTLdb ID & Pubmed ID \\
\hline Average daily gain (between 56 and 83 weeks) & $33609760: 33760089$ & 13957 & $19389264[51]$ \\
Body weight (at 83 weeks) & $42319448: 42469778$ & 13934 & 19389264 \\
Average daily gain (between 43 and 56 weeks) & $42319448: 42469778$ & 13950 & 19389264 \\
Body weight (at 43 weeks) & $39786167: 39936497$ & 13923 & 19389264 \\
Milk yield & $43302377: 51178327$ & 13818 & $19320771[52]$ \\
Milk lactose yield & $43302377: 51178327$ & 13819 & 19320771 \\
Milk yield & $43302377: 51178327$ & 13820 & 19320771 \\
Milk lactose yield & $43302377: 51178327$ & 13821 & 19320771 \\
Milk fat percentage & $6458777: 36327544$ & 14243 & $21749424[53]$ \\
Milk fat percentage & $6458777: 36327544$ & 14244 & 14245 \\
Milk fat percentage & $6458777: 36327544$ & 14246 & 21749424 \\
Milk yield & $6458777: 36327544$ & 21749424 & 21749424 \\
\hline
\end{tabular}



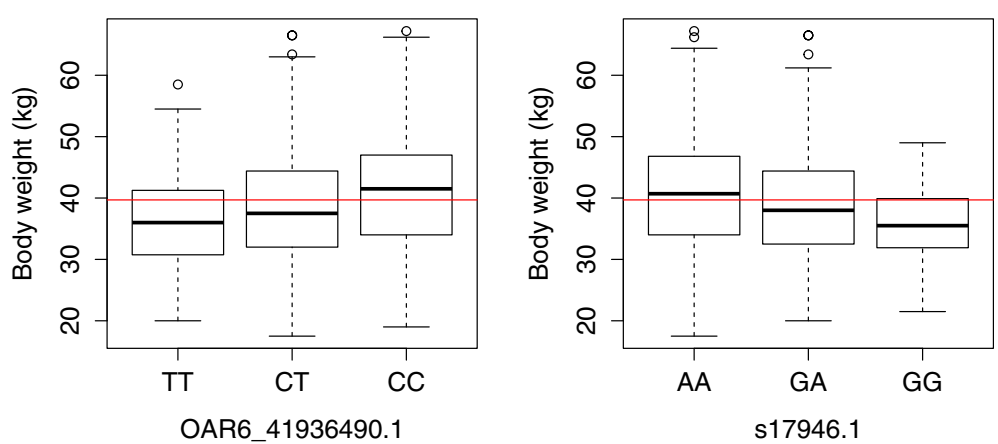

Fig. 6 Estimates of SNP effects. Boxplots of the genotypes of the two SNPs that are most significantly associated (OAR6_41936490.1 and s17946.1) with body weight in the Australian Merino sheep. The horizontal red line shows overall population mean weight values and lines within the boxes are the median weights within a genotypic group. There were few extreme values (outliers), which are indicated by circles. Note that both SNPs are in LD and, most likely, they track the same QTL

Several candidate genes are present in the $2.41 \mathrm{Mb}$ region on OAR6, although some are unlikely due to the lack of direct syntenic relationships with the human genome. It is likely that body size traits associated with this region are associated with genes that are expressed in affected tissues such as skeletal muscle and to a lesser extent adipose tissue, both of which have interactive functions. Gene expression data for adipose tissue depots and skeletal muscle from ovine late gestation fetuses and lambs indicate that LAP3, mediator complex subunit 28 (MED28), family with sequence similarity 184, member B (FAM184B), DDB1 and CUL4 associated factor 16 (DCAF16), NCAPG and LCORL genes are all expressed in these tissues and associated with permissive chromatin marks (Vuocolo and Tellam, personal communication). Moreover, it has been demonstrated that the expression of NCAPG and LCORL in bovine adipose and muscle tissues is associated with feed intake and average daily gain [33]. By combining these data and the information described above, one can narrow down the list of positional candidate genes to NCAPG and $L C O R L$.

Table 4 Estimates of haplotype effects of the QTL for body weight

\begin{tabular}{lll}
\hline Haplotype & $\beta^{\mathrm{a}}$ & $P$-value \\
\hline AATC & 0.166 & 0.86752 \\
AGTT & -0.095 & 0.27794 \\
AGGT & 0.049 & 0.00155 \\
GATT & -0.164 & 0.01857 \\
GATC & -0.158 & 0.00288 \\
GAGT & -0.330 & 0.23310 \\
GGGT & 0.451 & 0.19978
\end{tabular}

The $P$-value of the haplotype effect in a linear mixed model including a mean, a random sire effect and multiple regressions on the haplotypes was equal to 0.0008

${ }^{a}$ Estimates of regression coefficients $(\beta)$ in phenotypic standard deviation (STD) units of the trait based on phenotypes

${ }^{\mathrm{b}} P$-values for the test of $\beta \neq 0$
NCAPG is involved in the condensation and stabilization of chromosomes during meiosis and mitosis. A non-synonymous mutation I442M (c.1326T $>$ G) in the NCAPG gene is strongly associated with fetal growth and carcass traits in cattle [39], although this variant was excluded as a contributor to carcass weight in another cattle population [37]. Two studies have indirectly linked this NCAPG variant with arginine metabolism [40, 44]. Arginine has a major role in fetal and adult growth and more specifically in skeletal muscle growth $[45,46]$. Close to the NCAPG gene is LCORL, which encodes a liganddependent nuclear receptor corepressor-like protein. Interestingly, in most mammals the amino-terminal region of this protein contains a poly-alanine tract, part of which is encoded by a pure trinucleotide repeat. More generally, this type of repeats is known to be susceptible to polymorphic variation [47], which often leads to altered protein function and disease. It is also often subject to natural selection, which may contribute to species-specific morphological differences [48-50]. Indeed, human expressed sequence tags provide evidence for polymorphic repeat expansions and contractions in this region of LCORL. The first exon of the ovine $L C O R L$ has not yet been annotated and it should be investigated for polymorphisms. Sequencing is currently in progress to identify the causal mutation.

\section{Conclusions}

In summary, our GWAS identified 39 SNPs associated with body weight in sheep and we found a major QTL region that spans a $2.41 \mathrm{Mb}$ region on OAR6. Within this region, the genes NCAPG and LCORL are likely candidate genes for $\mathrm{BW}$. The region that harbors the NCPAG and LCORL genes on OAR6 is highly conserved among mammalian species and multiple body size traits in various species have been associated with this syntenic region, which may reflect that the underlying 
biological mechanisms share a common ancestry. These findings should facilitate the discovery of causal variants for BW and contribute to marker-assisted selection.

\section{Additional files}

Additional file 1: Table S1. Number of SNPs before and after quality control and average distances between adjacent SNPs on each chromosome. (DOCX $16 \mathrm{~kb}$ )

Additional file 2: Table S2. The 39 SNPS that have a significant association with body weight in 1743 Merino sheep. This table presents the chromosomal positions of 39 genome-wide significant SNPs with MAF, P-values as well as the proportion of genetic variance and allele substitution effects that can be attributed to each SNP. (DOCX $23 \mathrm{~kb}$ )

Additional file 3: Table S3. Percentages of genetic variance explained by each chromosome. This table presents the percentages of genetic variance explained by each chromosome obtained by fitting all chromosomes simultaneously in the GCTA software. (DOCX $19 \mathrm{~kb}$ )

\section{Competing interests}

The authors declare that they have no competing interests.

\section{Authors' contributions}

HAM, CG and SC carried out the analyses, RT provided functional analyses of results, CG designed the project, CG and PK advised on the project, MHF phased the genotypes. All authors read and approved the final manuscript.

\section{Acknowledgements}

This project was funded by the Sheep Cooperative Research Centre (Sheep CRC), Australia. CG and PK were supported by an Australian Research Council Discovery Project DP130100542. CG and HAM also acknowledge support by a grant from the Next-Generation BioGreen 21 Program (No. PJ01134906), Rural Development Administration, Republic of Korea.

\section{Author details}

${ }^{1}$ School of Environmental and Rural Science, University of New England, Armidale, NSW 2351, Australia. ${ }^{2}$ School of Science and Technology, University of New England, Armidale, NSW 2351, Australia. ${ }^{3}$ CSIRO Animal, Food and Health Sciences, Queensland Bioscience Precinct, St. Lucia, QLD 4067, Australia.

Received: 5 July 2014 Accepted: 23 July 2015

Published online: 14 August 2015

\section{References}

1. Lango Allen H, Estrada K, Lettre G, Berndt SI, Weedon MN, Rivadeneira F, et al. Hundreds of variants clustered in genomic loci and biological pathways affect human height. Nature. 2010;467:832-8.

2. Gu X, Feng C, Ma L, Song C, Wang Y, Da Y, et al. Genome-wide association study of body weight in chicken F2 resource population. PLoS One. 2011;6:e21872

3. Schneider JF, Rempel LA, Rohrer GA. Genome-wide association study of swine farrowing traits. Part I: genetic and genomic parameter estimates. J Anim Sci. 2012;90:3353-9.

4. Schneider JF, Rempel LA, Snelling WM, Wiedmann RT, Nonneman DJ, Rohrer GA. Genome-wide association study of swine farrowing traits. Part II: Bayesian analysis of marker data. J Anim Sci. 2012;90:3360-7.

5. Signer-Hasler $H$, Flury C, Haase B, Burger D, Simianer $H$, Leeb T, et al. A genome-wide association study reveals loci influencing height and other conformation traits in horses. PLoS One. 2012;7, e37282.

6. Yang J, Benyamin B, McEvoy BP, Gordon S, Henders AK, Nyholt DR, et al. Common SNPs explain a large proportion of the heritability for human height. Nat Genet. 2010;42:565-9.

7. Maltecca C, Weigel KA, Khatib H, Cowan M, Bagnato A. Whole-genome scan for quantitative trait loci associated with birth weight, gestation length and passive immune transfer in a Holstein $x$ Jersey crossbred population. Anim Genet. 2009:40:27-34.
8. McClure MC, Morsci NS, Schnabel RD, Kim JW, Yao P, Rolf MM, et al. A genome scan for quantitative trait loci influencing carcass, post-natal growth and reproductive traits in commercial Angus cattle. Anim Genet. 2010:41:597-607.

9. Cole JB, Wiggans GR, Ma L, Sonstegard TS, Lawlor TJ, Crooker BA, et al. Genome-wide association analysis of thirty one production, health, reproduction and body conformation traits in contemporary U.S. Holstein cows. BMC Genomics. 2011;12:408.

10. Mizoshita K, Takano A, Watanabe T, Takasuga A, Sugimoto Y. Identification of a 1.1-Mb region for a carcass weight QTL onbovine chromosome 14. Mamm Genome. 2005;16:532-7.

11. Nishimura S, Watanabe T, Mizoshita K, Tatsuda K, Fujita T, Watanabe N, et al. Genome-wide association study identified three major QTL for carcass weight including the PLAG1-CHCHD7 QTN for stature in Japanese Black cattle. BMC Genet. 2012:13:40

12. Setoguchi $K$, Furuta M, Hirano T, Nagao T, Watanabe $T$, Sugimoto $Y$, et al Cross-breed comparisons identified a critical 591-kb region for bovine carcass weight QTL (CW-2) on chromosome 6 and the lle-442-Met substitution in NCAPG as a positional candidate. BMC Genet. 2009:10:43.

13. Karim L, Takeda H, Lin L, Druet T, Arias JAC, Baurain D, et al. Variants modulating the expression of a chromosome domain encompassing PLAG1 influence bovine stature. Nat Genet. 2011;43:405-13.

14. Gudbjartsson DF, Walters GB, Thorleifsson G, Stefansson H, Halldorsson BV, Zusmanovich $P$, et al. Many sequence variants affecting diversity of adult human height. Nat Genet. 2008;40:609-15.

15. Weedon MN, Lango $H$, Lindgren CM, Wallace C, Evans DM, Mangino M, et al. Genome-wide association analysis identifies 20 loci that influence adult height. Nat Genet. 2008:40:575-83.

16. Pausch H, Flisikowski K, Jung S, Emmerling R, Edel C, Götz KU, et al. Genome-wide association study identifies two major loci affecting calving ease and growth-related traits in cattle. Genetics. 2011;187:289-97.

17. Pryce JE, Hayes BJ, Bolormaa S, Goddard ME. Polymorphic regions affecting human height also control stature in cattle. Genetics. 2011;187:981-4.

18. Utsunomiya YT, do Carmo AS, Carvalheiro R, Neves HHR, Matos MC, Zavarez $L B$, et al. Genome-wide association study for birth weight in Nellore cattle points to previously described orthologous genes affecting human and bovine height. BMC Genet. 2013;14:52.

19. Lee SH, Choi BH, Lim D, Gondro C, Cho YM, Dang CG, et al. Genome-wide association study identifies major loci for carcass weight on BTA14 in Hanwoo (Korean cattle). PLoS One. 2013;8, e74677.

20. Guo JZ, Jorjani H, Carlborg O. A genome-wide association study using international breeding-evaluation data identifies major loci affecting production traits and stature in the Brown Swiss cattle breed. BMC Genet. 2012;13:82.

21. Hu ZL, Park CA, Wu XL, Reecy JM. Animal QTLdb: an improved database tool for livestock animal QTL/association data dissemination in the postgenome era. Nucleic Acids Res. 2013;41:D871-9.

22. Riggio V, Matika O, Pong-Wong R, Stear MJ, Bishop SC. Genome-wide association and regional heritability mapping to identify loci underlying variation in nematode resistance and body weight in Scottish Blackface lambs. Heredity (Edinb). 2013:110:420-9.

23. Zhang L, Liu J, Zhao F, Ren H, Xu L, Lu J, et al. Genome-wide association studies for growth and meat production traits in sheep. PLoS One. 2013;8, e66569.

24. Jonas E, Thomson PC, Raadsma HW. Genome-wide association study and fine mapping of QTL on OAR 21 for body weight in sheep. In Proceeding of the $9^{\text {th }}$ World Congress on Genetics Applied to Livestock Production: 1-6 August 2010; Leipzig. 2010. http://www.kongressband.de/wcgalp2010/assets/pdf/0938.pdf.

25. Scheet $P$, Stephens M. A fast and flexible statistical model for large-scale population genotype data: applications to inferring missing genotypes and haplotypic phase. Am J Hum Genet. 2006;78:629-44.

26. Gilmour AR, Thompson R, Cullis BR. Average information REML: An efficient algorithm for variance parameter estimation in linear mixed models. Biometrics. 1995:51:1440-50

27. Aulchenko YS, Ripke S, Isaacs A, van Duijn CM. GenABEL: an R package for genome-wide association analysis. Bioinformatics. 2007;23:1294-6.

28. Yang J, Lee SH, Goddard ME, Visscher PM. GCTA: a tool for genome-wide complex trait analysis. Am J Hum Genet. 2011;88:76-82.

29. Ferdosi MH, Kinghorn BP, van der Werf JH, Gondro C. Detection of recombination events, haplotype reconstruction and imputation of sires using half-sib SNP genotypes. Genet Sel Evol. 2014;46:11. 
30. Browning BL, Browning SR. Rapid and accurate haplotype phasing and missing data inference for whole genome association studies using localized haplotype clustering. Am J Hum Genet. 2007:81:1084-97.

31. Barrett JC, Fry B, Maller J, Daly MJ. Haploview: analysis and visualization of LD and haplotype maps. Bioinformatics. 2005;21:263-5.

32. Gabriel SB, Schaffner SF, Nguyen H, Moore JM, Roy J, Blumenstiel B, et al. The structure of haplotype blocks in the human genome. Science. 2002;296:2225-9.

33. Lindholm-Perry AK, Kuehn LA, Oliver WT, Sexten AK, Miles JR, Rempel LA, et al. Adipose and muscle tissue gene expression of two genes (NCAPG and LCORL) located in a chromosomal region associated with cattle feed intake and gain. PLoS One. 2013;8, e80882.

34. Cohen-Zinder M, Seroussi E, Larkin DM, Loor JJ, Everts-van der Wind A, Lee $J$, et al. Identification of a missense mutation in the bovine $A B C G 2$ gene with a major effect on the QTL on chromosome 6 affecting milk yield and composition in Holstein cattle. Genome Res. 2005;15:936-44.

35. Zheng X, Ju ZH, Wang J, Li QL, Huang JM, Zhang AW, et al. Single nucleotide polymorphisms, haplotypes and combined genotypes of LAP3 gene in bovine and their association with milk production traits. Mol Biol Rep. 2011;38:4053-61.

36. Setoguchi K, Watanabe T, Weikard R, Albrecht E, Kühn C, Kinoshita A, et al. The SNP C.1326T > G in the non-SMC condensin I complex, subunit G (NCAPG) gene encoding a p.lle442Met variant is associated with an increase in body frame size at puberty in cattle. Anim Genet. 2011;42:650-5.

37. Gutierrez-Gil B, Wiener P, Williams $J$, Haley CS. Investigation of the genetic architecture of a bone carcass weight QTL on BTA6. Anim Genet. 2012;43:654-61.

38. Daetwyler HD, Swan AA, van der Werf JH, Hayes BJ. Accuracy of pedigree and genomic predictions of carcass and novel meat quality traits in multibreed sheep data assessed by cross-validation. Genet Sel Evol. 2012;44:33.

39. Eberlein A, Takasuga A, Setoguchi K, Pfuhl R, Flisikowski K, Fries R, et al. Dissection of genetic factors modulating fetal growth in cattle indicates a substantial role of the non-SMC condensin I complex, subunit G (NCAPG) gene. Genetics. 2009;183:951-64.

40. Weikard R, Altmaier E, Suhre K, Weinberger KM, Hammon HM, Albrecht E, et al. Metabolomic profiles indicate distinct physiological pathways affected by two loci with major divergent effect on Bos taurus growth and lipid deposition. Physiol Genomics. 2010;42A:79-88.

41. Olsen HG, Meuwissen $\mathrm{TH}$, Nilsen $H$, Svendsen $M$, Lien S. Fine mapping of quantitative trait loci on bovine chromosome 6 affecting calving difficulty. J Dairy Sci. 2008;91:4312-22.

42. Bongiorni S, Mancini G, Chillemi G, Pariset L, Valentini A. Identification of a short region on chromosome 6 affecting direct calving ease in Piedmontese cattle breed. PLoS One. 2012;7, e50137.

43. Horikoshi M, Yaghootkar H, Mook-Kanamori DO, Sovio U, Taal HR, Hennig BJ, et al. New loci associated with birth weight identify genetic links between intrauterine growth and adult height and metabolism. Nat Genet. 2013:45:76-82.

44. Widmann P, Reverter A, Fortes MRS, Weikard R, Suhre K, Hammon H, et al. A systems biology approach using metabolomic data reveals genes and pathways interacting to modulate divergent growth in cattle. BMC Genomics. 2013;14:798.

45. Wu G, Bazer FW, Davis TA, Kim SW, Li P, Marc Rhoads J, et al. Arginine metabolism and nutrition in growth, health and disease. Amino Acids. 2009:37:153-68.

46. Yao K, Yin YL, Chu W, Liu Z, Deng D, Li T, et al. Dietary arginine supplementation increases mTOR signaling activity in skeletal muscle of neonatal pigs. J Nutr. 2008;138:867-72.

47. Whan V, Hobbs M, McWilliam S, Lynn DJ, Strandberg Lutzow Y, Khatkar M, et al. Bovine proteins containing poly-glutamine repeats are often polymorphic and enriched for components of transcriptional regulatory complexes. BMC Genomics. 2010;11:654.

48. Haerty W, Golding GB. Genome-wide evidence for selection acting on single amino acid repeats. Genome Res. 2010;20:755-60.

49. Mularoni L, Ledda A, Toll-Riera M, Alba MM. Natural selection drives the accumulation of amino acid tandem repeats in human proteins. Genome Res. 2010;20:745-54.

50. Fondon 3rd JW, Garner HR. Molecular origins of rapid and continuous morphological evolution. Proc Natl Acad Sci U S A. 2004;101:18058-63.

51. Raadsma HW, Thomson PC, Zenger KR, Cavanagh C, Lam MK, Jonas E, et al. Mapping quantitative trait loci (QTL) in sheep. I. A new male framework linkage map and QTL for growth rate and body weight. Genet Sel Evol. 2009;41:34.
52. Arnyasi M, Komlosi I, Lien S, Czegledi L, Nagy S, Javor A. Searching for DNA markers for milk production and composition on chromosome 6 in sheep. J Anim Breed Genet. 2009;126:142-7.

53. Garcia-Fernandez M, Gutierrez-Gil B, Sanchez JP, Moran JA, Garcia-Gamez E, Alvarez $L$, et al. The role of bovine causal genes underlying dairy traits in Spanish Churra sheep. Anim Genet. 2011;42:415-20.

\section{Submit your next manuscript to BioMed Central and take full advantage of:}

- Convenient online submission

- Thorough peer review

- No space constraints or color figure charges

- Immediate publication on acceptance

- Inclusion in PubMed, CAS, Scopus and Google Scholar

- Research which is freely available for redistribution 